\title{
Article
}

\section{'I see my section scar like a battle scar': The ongoing embodied subjectivity of maternity}

\section{Sally Johnson}

\section{University of Bradford, UK}

\section{Abstract}

Though many women may be dissatisfied with their bodies, maternity represents a period when the body deviates significantly from Western beauty ideals. However, the developing corpus of literature is contradictory and there is limited knowledge about the longer-term implications of maternity. Further, much of the early postpartum literature focuses on body image, precluding consideration of broader embodiment and other potential issues. Taking account of recent feminist critiques about acknowledging women's reproductive capacities, the study reported here explores the embodied subjectivity of longerterm bodily changes resulting from pregnancy, childbirth and early mothering. The data explored are from three focus groups. Mothers were recruited from two universities in the North of England, UK. Data were transcribed and analysed thematically and discursively using a feminist and poststructuralist 
approach, while also taking account of where language was elusive. A number of contradictory, yet interrelated embodied constructions were identified including the aesthetic, the maternal, the suffering/sentient, the strong and the embarrassing body. New insights are offered, in that, not only are the postpartum body and the 'work of mothering' inextricably linked, but also that maternal embodied identities are in continuous process across the life course and may have implications for health and well-being.

\section{Keywords}

Postpartum body, mothers' bodies, motherhood, embodiment, ageing

\section{Corresponding author:}

Sally Johnson, University of Bradford, Richmond Road, Bradford, UK Email: s.e.johnson2@bradford.ac.uk

\section{Background}

The term 'normative discontent' was coined to emphasise that, even under normal circumstances, many Western women are dissatisfied with their bodies, desiring to be thinner (see Rodin, Silberstein \& Striegel-Moore, 1984). Pregnancy and postpartum represent a period when the body deviates significantly from White, Western beauty ideals (Johnson, Burrows \& Williamson, 2004), however, the literature in this area is somewhat contradictory 
with certain research suggesting that some women are satisfied with their bodies postpartum (e.g. Carter-Edwards et al., 2010; Strang \& Sullivan, 1985), while other literature reports dissatisfaction (e.g. Clark, Skouteris, Wertheim, Paxton \& Milgrom, 2009; Gjerdingen, Fontaine, Crow, McGovern, Center \& Miner, 2009; Hodgkinson, Smith \& Wittkowski, 2014; Pauls, Occhino \& Dryfhout, 2008; Rallis Skouteris, Wertheim, \& Paxton, 2007; Upton \& Han, 2003). In addition, much of the previous literature is quantitative; a recent review of qualitative literature on body image during the perinatal period suggests more complexity than can be captured in self-report measures (Watson, Fuller-Tyszkiewicz, Broadbent \& Skouteris, 2015).

As well as this focus on quantitative methodology, much of the previous literature has concentrated on body image (external shape and weight in relation to standards for female beauty), precluding consideration of broader embodiment, how one inhabits the body, and other potential issues. However, some research does capture the complexity of bodily changes postpartum. Jordan, Capdevila and Johnson (2005) used Q methodology to explore the variety of understandings of women who had given birth within the previous three years. Six dominant narratives were identified that emphasised the concerns of new mothers. These included 'family centred', 'stressed', 'happy mothers', 'missing personal space', 'supportive family' and 'mother/child 
orientated'. What is interesting is that body image concerns, though present in some narratives, were only partially represented, and of variable concern. However, studies highlighting this complexity are rare, even within the critical feminist literature. Fox and Neiterman $(2015$, p. 627) note that little attention has been paid to women's changing bodies in research on the early experiences of motherhood. Further, they argue that the literature that does focus on bodily changes does not do so in relation to the 'work of mothering'.

Nonetheless, there is some feminist-informed research on the postpartum body involving critical theorisation of maternal embodiment (e.g. Bojorquez-Chapela, Unikel, Mendoza \& de Lachica 2014; Fox \& Neiterman, 2015; Nicolson, Fox \& Heffernan, 2010; Upton \& Han, 2003; Warin, Turner, Moore \& Davies, 2008). For instance, using theorisation located in the academic study of embodiment and of gender (e.g. Bordo, 1993; Foucault, 1981; Shilling, 1993), Nicolson et al. (2010) explore the implications of historically and culturally located embodied subjectivity in women's stories of their pregnant and postnatal body, thus providing a more socially contextualised account. Findings from of more contextualise research indicate that, more recently, mothers may be under greater pressure than previous generations because ideals for beauty and body size have changed over time. In addition, mothers are exposed to 'celebrity mums' in the media which may put them 
under unrealistic pressure to quickly return to their pre-pregnancy body (Nicolson et al., 2010; Roth, Homer \& Fenwick, 2012). However, not all support this view, with Fern, Buckley and Grogan (2012) arguing that the mothers in their sample saw celebrity images as unrealistic and felt protected because of this realisation. However most of these mothers were recruited from a breastfeeding support group which might have offered a degree of protection. Other literature also considers broader issues than body image, for instance, the impact of maternity on sexual functioning (e.g. Pauls et al., 2008) and changes to the skin, including stretch marks (e.g. Harper \& Rail, 2011).

Despite this developing literature on the postpartum body, there is limited knowledge about the longer-term implications of pregnancy, childbirth and early mothering. Much of the research to date has focused on the early period after childbirth, with the majority of studies collecting data within the first few months (e.g. Carter-Edwards, et al., 2010; Clark et al., 2009; Gjerdingen et al., 2009; Pauls et al., 2008; Strang \& Sillivan, 1985) or up to a year after the birth of the child in a few studies (e.g. Fern et al., 2012; Rallis et al., 2007). However, there is the suggestion that issues associated with maternity may have longer-term consequences in the small number of studies that have collected relevant data sometime after childbirth. For instance, Montemurro and Gillen (2013) found that mothers in their sample (aged from 20 to 68 ) described largely negative 
ways in which their bodies had changed permanently as a result of maternity, particularly their breasts. However, being a mother may protect women against body dissatisfaction as some researchers have found that motherhood represents a shift in focus from the body as a personal project, to a more relational identity; at least for a period of time (e.g. Bojorquez-Chapela et al., 2014; Fox \& Neiterman, 2015; Warin et al., 2008). In addition Woolhouse, McDonald and Brown (2012) investigated sexual intimacy between 2.5 and 3.5 years after childbirth. They concluded that pregnancy, childbirth and parenting can result in changes to libido that place a strain on intimate relationships and feelings about sex and sexuality, as women can feel 'guilt' and 'failure' in relation to the 'have it all' construction of motherhood. However, this impact was not just as a result of body dissatisfaction but also factors such as extreme tiredness and changes in lifestyle. Similarly, the study reported earlier, that suggests that bodily changes may be a relatively low priority in comparison to women's new roles as a mother (Jordan et al., 2005). Thus, there are some emerging studies that indicate the broadness of longer-term maternal embodiment, that is, beyond body image concerns.

Developing this further, as Hollway (2016) argues, there is a need for feminists to theorise the psychological implications of women's reproductive bodies over the life course in a way that recognised that, for those who become 
mothers, maternal identity is a continuing process. To develop this critical psychological feminist literature further, the body in the study reported here is conceptualised as not simply governed by biological needs or determined by social forces but as an emergent material phenomenon that shapes as well as is shaped by the social (Shilling, 2012). Further, Hollway (2016) argues, in relation to becoming a mother, that the dominant social constructionist approach within feminist psychology focusing as it does on language, offers a somewhat 'thin' theorisation of embodied maternal subjectivity. She argues that this theorisation negates a more extensive exploration of the corporeality of women's reproductive capacities. As she puts it; 'by implying gender is a social construction it encourages us to bracket off the implications of reproductive biology' (Hollway, 2016, p. 139). Therefore, though the research reported here explores the social construction of the body through an analysis of language, it also pays attention to the materiality of women's reproductive bodies by focusing on aspects of their embodiment that might be more difficult to put into words. As such, it aims to explore the embodied subjectivity of longer-term bodily changes resulting from pregnancy, childbirth and early mothering.

\section{About the study}

Women were recruited to take part in a focus group. Three focus groups were conducted to represent diversity in terms of the time that had elapsed 
since the birth of a child, and, in addition, allow for the exploration of potential generational issues. The focus groups were constituted as followed: at between 5 and $10(\mathrm{~N}=4), 11$ and $20(\mathrm{~N}=5)$, and over 20 years $(\mathrm{N}=3)$ since the birth of their last child. Focus groups were chosen over individual interviews as they more closely mirror 'naturalistic' conversation and interaction, and therefore how understandings are negotiated in social contexts (Forrester, 2010; Wilkinson, 2004).

Recruitment took place via an advert placed in a university staff newsletter (circulated to all staff with an email address) and through snowball sampling in the same and in another university in the North of England, UK. The advert stated the aim of the study, that it would involve taking part in a group discussion lasting around an hour to an hour and a half which would be held at the University and the inclusion criteria. The inclusion criteria were that participants had to have given birth to at least one child; that it was between 5 and 10, 11 and 20, or over 20 years since the birth of their last child; they were over 18 years of age; were able to speak English; and did not have a current mental health problem. No incentives to participate were offered. Those who expressed an interest were sent an information sheet and asked to contact me again if they wished to participate. The study generated much interest (36 potential participants contacted me), though the numbers participating were 
lower than anticipated due to practicalities related to the timing of the groups and last minute cancellations due to work commitments or illness. Though diversity was sought, the sample was somewhat limited by those willing to take part and by the location. Therefore, all were educated to at least A level or equivalent, with seven having postgraduate qualifications; most were in professional/managerial occupations, though one was not working, one was a student and one a cleaner; most identified as middle class, though three as working class; most reported their national identity as British, though one as English and one as Welsh; and most reported the ethnic group to which they consider they belonged as either White or White British, with one as Asian. Eight participants had two children, three had three children and one had seven children. Those in focus group one (youngest child aged between 5 and 10) were aged either between 31 and $40(\mathrm{~N}=1)$ or 41 and $50(\mathrm{~N}=3)$; those in focus group two (youngest child aged between 11 and 20) were aged between 41 and $50(\mathrm{~N}=2)$ or 51 and $60(\mathrm{~N}=3)$ and those in focus group three (youngest child aged over 20) were aged between 41 and $50(\mathrm{~N}=1)$ or 51 and $60(\mathrm{~N}=2)$. None of the women talked about difficulties conceiving, having any previous pregnancy loss or any other significant issues in their reproductive histories, though these data were not specifically sought. However, one participant did talk about a particularly traumatic birth. 
The focus groups were conducted by me, with the aid of a research assistant who helped with practicalities and took notes. They took place in a private room at one of the universities. Participants were briefed to remind them of the purpose of the study, their ethical rights and asked to sign a consent form. They were then asked to complete a participant details form for demographic information. The broad topics of the focus group discussions aimed to explore bodily experiences of pregnancy and the early and longer-term period following childbirth, the impact of any changes on relationships, and any influences on the pregnant, or on mothers' bodies thought to be pertinent. Topic areas were introduced in an informal conversational way and one main generative question asked. For example, for the topic most pertinent to the current paper, participants were asked if they could tell me about any longerterm implications of pregnancy, childbirth and breastfeeding, including any bodily changes they put down to these. Prompts were prepared, though were often not needed, however, probes/clarifications were used to generate further discussion. Topics were initially generated by following the chronology of becoming a mother and, in part, through asking key informants (several mothers who fitted the inclusion criteria) what they would like to talk about if they were involved in such a discussion. Participants were given a verbal debriefing and a sheet at the end of the discussion that reminded them of how 
they could withdraw and information on sources of advice if taking part had raised any issues for them. Ethical approval was granted by the university at which the author works. The first two focus groups lasted just under an hour and 20 minutes and the third one just under an hour. All were conducted in 2015. The discussions were audio recorded and transcribed verbatim by the research assistant and check by me. Pseudonyms have been used to protect identity. In the analysis and discussion section quotes from participants in the three different focus groups are denoted by FG1, FG2 \& FG3 respectively. Capital letters within quotes denotes louder or exaggerated speech.

An initial thematic analysis (Braun \& Clarke, 2006) was undertaken with relevant discursive features noted (Parker, 2005; Potter, Edwards \& Wetherell, 1993) as well as where participants had difficulties in putting embodied subjectivity into words. These aspects were further analysed from a feminist poststructuralist perspective (Day, Johnson, Milnes \& Rickett, 2010; Gavey, 1989; Weedon, 1997), focusing on the construction and positioning of gendered subjectivities, which illuminate process of knowledge, agency and power. This involved identifying different discursive constructions mobilised around the body, links between these constructions and wider discourses, the subject positions that these constructions and discourses made available, and their implications for action and subjectivity (Willig, 2013). Analysis also involved 
paying attention to where language was elusive. The analysis was conducted by me. It was then sent to the research assistant who provided feedback which led to some further development of the themes, though mostly she confirmed that the analysis reflected her impressions of what had been conveyed. The contribution of the research team in the focus groups is included in the analysis. We are both mothers, and as such took an active part in the discussions by openly sharing our own experiences in response to what was being said, though trying not to lead the discussions in a particular direction. A pseudonym is used for the contribution of the research assistant and consent to use her data was given. Data extracts have been selected to typically illustrate the key ways in which embodied subjectivity was constructed and conveyed as well as counter constructions. This process of analysis resulted in the identification of a number of contradictory, yet interrelated embodied constructions including the aesthetic, the maternal, the suffering/sentient, the strong and the embarrassing body.

\section{Analysis and discussion}

\section{The aesthetic body}

Within a discourse of the White, Western beauty ideal, a number of participants constructed the post pregnant body in negative terms and expressed dissatisfaction with appearance. Dissatisfaction related to 
transgressing ideals for hegemonic feminine beauty was evident through the use of negative language and imagery such as 'shocking', 'wobbly', 'saggy', 'repulsive', 'disgusting', 'droopy'. This transgression was not only immediately postpartum but also in the longer-term. For instance Danielle said:

I think there's lots of other sags and bumps and bits of stuff... I would attribute general kind of SQUISHINESS (laughter)... to having had children, because it wasn't like that before (FG1)

and Sandra:

I think I feel less positive about my body, how attractive it feels to me (FG2)

A metaphor of the body, particularly the stomach, as being elastic was drawn upon to describe its potential for regaining its previous shape and tone: for example, 'everything stretches [in pregnancy] so it's got to pop back' (Victoria FG3). Similarly, Roth et al. (2012) label the key construction of the postpartum body in Australian leading women's magazines as 'bouncing back'. The 'elastic' metaphor conveys a sense of maternity posing a threat to idealised young, tight bodies (Malacrida \& Boutlon, 2012). Indeed, for some there had been a dawning realisation that it doesn't necessarily work in this way: 'second time I realised it wouldn't ping back' (Emma FG1). In contrast, the metaphor of the elastic body worked more effectively for others. For instance: 
I'm quite lucky in that like immediately after having [first child] everything just went shhhup [implying an elastic-like contraction] within two weeks my stomach was flat again and with the twins I bounced back bodily-wise really, really well (Vanessa FG2)

However, this sense of gratitude for regaining the pre-pregnancy body further underscores the importance of conforming to acceptable female bodily aesthetics as soon as possible after pregnancy, and the relationship between youthfulness and attractiveness. In terms of the post-pregnant body, though some described returning to 'normal' fairly quickly and putting this down to luck or being automatic, implying that they did not have to do anything, others spoke of the body as a project that needing to be worked on and controlled in order to conform to feminine beauty. This work was evident in terms used such as 'reining it in' (Victoria, FG3), as 'time to bring back what I had before' (Danielle, FG1). Dominant ideologies of the White, Western beauty ideal include, for instance, the body as 'something that is to be displayed and preserved... a good in and of itself, rather than a means of achieving something else' (Moore, 2010, p. 110). As Witz (2000) puts it, women are seen as their bodies. Digression from idealised femininity (e.g. leaking fluids, lumps and bumps and signs of ageing) is stigmatised (Chrisler, 2011). Therefore women's bodies are 
disciplined through self-surveillance (Foucault, 1995) and thereby worked upon as projects (Foucault, 1981; Shilling, 2012).

Aesthetics were also discussed in relation to other parts of the body such as changing breasts, for the better or worse. For example, Stephanie (FG3) said:

so I MEAN I THINK MY BREASTS ARE REALLY SMALL and I kind of feel as though they've been because of breastfeeding ... empty, empty purses (laughs), tiny, tiny I can't get a bra in a 36A very easily (laughs) Though, Susan said:

I never had boobs when I got pregnant, I was like a double A so it's had ... a different impact on me whereas I've got quite nice boobs now and I had hideous ones before (FG1)

Others in the group responded to Susan by saying 'that's great', 'excellent', and in doing so, conveyed a celebratory tone that emphasised the importance of having appropriate breasts, further reinforcing what is acceptable in terms of feminine beauty. However, there was a sense of uncertainty about the cause of changes to the body more generally, and breasts specifically. For instance, Jessie (FG1) questioned whether the negative changes that Lucy described in relation to her breasts becoming 'almost concave' and 'desiccated on the top' were due to age or maternity, saying 'everything sags a bit [with age]'. 
Therefore changes were, at times, potentially attributed to ageing, and this association was negative, thus the ageing body was also constructed as transgressing ideals for feminine beauty, positioning older women's bodies as threatening and stigmatized (Chrisler, 2011). Growing older for Western, and particularly for middle-class women, means looking 'good for your age', or 'growing old gracefully' (Baraitser, 2014).

Scarring was also talked about in negative terms. Sandra spoke about the implications of her Caesarean scar:

the MAIN problem that I don't like is that it [her Caesarean scar] kind of somehow affects the way my stomach sort of DROOPS over it... I didn't like that it changed (FG2)

In addition, scarring from stretch marks ascribed to maternity was also largely constructed negatively, particularly on the buttocks and stomach. In the context of describing that she felt she now had 'nice boobs', Susan (FG1) said 'but on the negative side l've now got stretchmarks all over my BUM and I HATE THAT, I ABSOLUTELY HATE THAT'. Similarly, as outlined above, though Vanessa (FG2) classed herself as 'lucky' to have regained a flat stomach quickly postpartum, she was less positive about stretch marks on her buttocks. When I asked her how she felt about them she said: 'not happy, l've got used to them eventually but not happy'. Victoria (FG 3) talked about the stretch marks on her 
stomach as having a negative impact on her, saying 'I was very conscious of the crepe papery tummy, STILL AM REALLY'. Stretch marks were also constructed as limiting what could be worn, particularly in relation to more revealing clothing such as swimwear. However, counter to these negative constructions, others described little or no impact from scarring. For instance, Beth (FG2), responding to Sandra's negative description of the impact of her Caesarean scar, said 'my scar doesn't bother me at all'. Therefore, most, though not all, aligned themselves with the post maternity body transgressing a 'body-as-an-external-aesthetic-object' construction of femininity (Bekker, 2000, p. 23) in some way.

However, sexuality was not always linked to attractiveness. As noted earlier, Sandra (FG2) said she thought that her body was less attractive now but 'I don't think that necessarily has an impact on our relationship'. Similarly, Thorpe, Fileborn, Hawkes, Pitts and Minichiello (2015) found that while older women in intimate relationships often reported being unhappy with their appearance, this was not as important to them in relationships. Nonetheless the presence of male partners, and what they might see at the birth was constructed as having a potential damaging effect on sexual relationships by a couple of participants. For instance, Susan (FG1) spoke of having a friend rather than her husband present at the birth because 'how could you possibly 
want to go there again when you've seen this child come out'. In addition, the vagina was spoken about as having changed in a negative way as a result of childbirth: 'but I do feel a lot more BAGGY down there (laughter) I mean I definitely not as tight as I would like to be' (Jessie FG1), implying it needs to be tighter for sexual satisfaction. According to Braun and Kitzinger (2001), in the West the desirable vagina is constructed as tight (though not too tight), mainly for men's pleasure; and a loose vagina therefore as not desirable. Similarly, Malacrida and Boutlon (2012) argue that against constructions of idealised female embodiment as young, smooth, sexual and tight, the stretching and messiness of vaginal birth is at odds with heteronormative sexual pleasure.

Though not all subscribed to the body-as-aesthetic-object construction of femininity in terms of weight and shape, participants in all the groups talked about some aspect of post maternity embodiment in terms of transgressing idealised forms of feminine attractiveness, some irreparably so. As women are seen as their bodies (Witz, 2000), and dominant versions of the White, Western beauty ideal are readily available, a limited range of subject positions are on offer in relation to the maternity. However, other versions of embodied subjectivity were deployed which helped participants manage these limiting positionings.

\section{The maternal body}


The body was constructed as relating to a discourse of maternity, that is, motherly qualities, in various ways. For some, motherhood was protective of bodily concerns, acting as a counter construction to the dominant White, Western beauty ideal, at least for a period of time. For instance, Danielle (FG1) countered the negative talk about the post-pregnancy body in her focus group by saying:

see I didn't feel like that, not when the children were little, it was only as they got a bit OLDER almost as when they're getting away from me and getting their own independence that I began to think that maybe I should begin to consider my body as MY OWN AGAIN... and I didn't actually feel bad about any of that at the time ... I PROBABLY FELT that the importance of my body was secondary

The body-as-aesthetic-object construction perpetuates the postpartum body as in need of repair, and new mothers are expected to regain their pre-pregnancy shape as soon as possible after the birth of a child (Upton \& Hans, 2003). However, Danielle's construction supports research that suggests that early motherhood may bring about a shift in focus to a more relational identity, thereby offering protection against social pressure for reparation (BojorquezChapela et al., 2014; Fox \& Neiterman, 2015; Warin et al., 2008); though the data suggests that there is a limit to this protection. While 'my body is my own 
again' may seem agentic, it also signals a time to return to an acceptable weight and shape, governed by the aesthetic body construction. Indeed, Danielle affirms this by stating 'and it was only two years ago that I thought now l'VE GOT TO LOSE WEIGHT', implying she was under an obligation and exercising self-surveillance.

Lack of time due to the tasks of motherhood also legitimated a lack of focus on the body as a project. For example, Stephanie (FG3) said, in relation to being 'fit' in her twenties, that she 'couldn't keep that up' due to the demands of motherhood and holding down a professional job, thereby resisting the dominant mothers 'can have it all' construction (Woolhouse et al., 2012). She said:

I sort of threw myself into it [motherhood] ... I mean when I see young mothers now doing everything I do sometimes wonder how they manage to do it really because I found it was quite enough to be a full-time mum and a full-time professional without thinking I need to train for the half marathon or anything as well. I think it was all too much so I kind of didn't bother for quite a long time Stephanie intimates that there might be a generational difference in that mothers were more protected from body image concerns in the past (Nicolson et al., 2010). Though for Danielle, who was younger (though none of the 
participants were particularly young), the maternity discourse was also protective. Therefore the counter discourse of maternity may offer a limited subject position that might be difficult to sustain because of celebrity culture and pressure on younger, and arguable less well educated and supported women than the current sample, to regain the pre-pregnancy weight and shape quickly (Nicolson et al., 2010; Roth, et al., 2012).

Time and maternity were also discussed in relation to sexuality. For instance, Jessie (FG1) talked about sex being a low priority for a considerable period of time post-pregnancy:

.... had a really long time when just his need were very peripheral to what was going on for me and $\mathrm{I}$ just it was like an additional kind of request on my time which was already overstretched and it was like 'really you wanna have sex now', just 'no', you know (laughter), so that was quite a long period really that was probably fairly miserable for him (laughter) and I was obviously just being fulfilled in other areas of my life and just didn't need that

Here maternity was again associated with excessive demands but also as being fulfilling in its own right. Jessie described her sex-life as improving after the birth of her third child that's like 14 years before we got to a good place again'. Though Lucy (FG1) also ascribed her lack of interest in sex to 
being 'too tired', she described a more negative, longer-term impact, in that her 'husband just got used to just never going there' which had had 'a lasting impact on our sex-life and I'm really GUTTED about that NOW'. Similarly, Woolhouse et al. (2012) highlight how excessive tiredness, changing lifestyles and body image issues lead to changes in libido and intimacy in relationships which, they argue, can bring about significant changes to the experience of sex and intimacy for some women. The implication for subjectivity is that women may feel a sense of failure and guilt in relation to high expectations of 'doing it all' constructions, as indicated by Lucy.

In addition, there was talk of the maternal body being incompatible with sexuality, especially in relation to breastfeeding. Jessie and Emma (FG1) both spoke about not wanting their husbands to touch their breasts because it just felt a bit wrong for them to be sexual when they were feeding things' (Jessie), and this having an impact on their sex-life. Similarly, others have highlight competing discourses of femininity in that, on the one hand women's bodies are seen as heteronormative sites of sexuality and pleasure, and on the other, as for asexual maternal nurturance (e.g. Malacrida \& Boulton, 2012; Woolhouse et al., 2012), reflecting the Madonna/whore dichotomy (Young, 2005).

The maternity discourse therefore makes available subject positions that can counter aesthetic feminine beauty and women can 'have it all' 
constructions, as it bring into play representations of intensive and good mothering (Hays, 1996) where their child's body becomes the project (Bojorquez-Chapela et al., 2014). However, as maternity is time limited, so is the protection it offers. As such, not being able to regain the pre-pregnant, younger, smoother, tighter and more sexual body, as well as tensions between Madonna/whore constructions, may have longer-term negative implications for embodied subjectivity.

\section{The suffering/sentient body}

The longer-term post-maternal body was constructed in several ways in relation to suffering and sentience, for instance, as resolving suffering previously associated with previously painful periods, as having the potential to experience ongoing sensations in the breasts and nipples associated with breastfeeding, and as causing temporary as well as longer-term suffering. Temporary suffering included pain on intercourse after vaginal delivery which was constructed as inhibited sexual relationships for a time. However, a prominent topic in all the focus groups was an association between maternity and ongoing stress incontinence. Potential links between incontinence, pregnancy and childbirth were made, though some questioned whether this was age related as well; 'that's not an age thing as well isn't it?' (Susan FG1). 
However, Beth (FG2) firmly attributed incontinence to a difficult birth; 'as a result of having [first child] I was incontinent'.

There was discussion about what could be done about stress incontinence, with talk about whether pelvic floor exercises made a difference; some claiming they did and others they didn't. A sense of obligation to engage in pelvic floor exercises was conveyed, though at times resisted. For example, Victoria (FG3) said:

but you're supposed to do your pelvic floors and all that business aren't you, I DON'T DO THEM, I DON'T, I've been told I should but...

Though Stephanie (FG3) implied that they may not be effective, which was portrayed as relieving guilt, though through mentioning guilt a moral imperative is further shored up:

somebody was telling me that that's been discredited...of certain methods of doing that which is reassuring (laughter) when you're been doing your pelvic floor for 12 years and it's not made any difference (laughter)

Victoria: well I feel less guilty about not doing them then

In the context of discussions about what can be done about incontinence, a sense of 'putting up' with problems was also communicated, for 
instance, Stephanie said 'I've been suffering with that [stress incontinence] for quite a long time' and as Sandra (FG2) put it 'we just accept things'. 'Suffering with that' and 'accepting things' convey a sense of the difficulty in putting such suffering into language.

A range of other health issues attributed to maternity were outlined. For example, Ruth (FG2) described having a hernia and Jaya (FG3) reported longterm effects of arthritis and calcium loss which she attributed to pregnancy. These health issues were conveyed in a somewhat descriptive way. Beth (FG2) exemplified this descriptive tone by saying 'have you got a big piece of paper?', and proceeded to outline, in a list like way, a number of health issues including a prolapse, incontinence and a hernia (which had been repaired twice). Beth described a particularly traumatic birth that had led to a number of longer-term health issues, however, she did not seem to indicate concerns about her body image more generally; as she indicated earlier, she was not bothered about her caesarean scar. Though it could be argued that list like manner in which she reported her health problems emphasised her suffering, the descriptive and factual way in which longer-term 'suffering' was conveyed could also be interpreted as a linguistic tool brought into play to handle a particular dilemma (Potter et al., 1993); in this instance, as a way of emphasising the pain and suffering that mothers endure but are not able to 
freely put into words. It has argued that sacrifice and pain are normatively understood as part of birthing, idealised womanhood and medical discourse (Malacrida \& Boulton, 2012). Therefore problems are potentially accepted in a stoical way, and downplayed as part and parcel of the consequences of maternity. Thus, the subject position of 'suffering in silence' that is expected of a selfless mother can have implications in that treatment might not be sought in a timely manner. Constraints on help seeking because of constructions of maternity and women's bodies are explored further in the final two themes.

\section{The strong body}

In contrast to the 'suffering' body, and as a counter discourse, women's bodies were also constructed as strong in relation to maternity. Military imagery was drawn upon to convey a sense of being proud of having something to show for having 'survived' the 'battle' of maternity, though not all subscribed to this:

Lucy: I see my scar, my section scar, as like a really good thing in many ways now

Researcher: in what ways?

Lucy: well it's kind of like a battle scar ... like a scar to show that you've been pregnant, it's kind of like... this is the wrong phrase but a badge of honour... 
Emma: I read an article about a woman who said... 'they're not stretchmarks... I'm a tiger who earned my stripes' (laughter) and I can remember thinking, you know that I wish I could feel like that about my stretch marks

Susan: I don't feel like that about my bum [referring to stretch marks] (FG1)

In a more general sense, Victoria (FG 3) spoke of women's bodies as having to be strong to cope with childbirth:

but if you think about what women's bodies have to go through and how strong they are to have to cope with that time and again, cos we don't just have one, oh no, we have half a dozen... but your body has to be strong to be able to cope with returning to normality Similarly, Woolhouse et al. (2012) found that, though some participants in their study described feeling unattractive due to body image issues resulting from pregnancy and childbirth, others described increased empowerment and respect for the body. However, in both the current and Woolhouse et al.'s study, the strong body was less prominent than other constructions. Nonetheless, the empowering tone of the strong body implies a feminist counter discourse to the weaker sex construction, though positioning women's bodies as having to be strong may limit subject positions available to them leading to a lack of 
acknowledgement of suffering, as strength is an assumed part of becoming and being a mother.

\section{The embarrassing body}

The language used, silences, shared understandings and laughter suggested a sense of embarrassment about certain aspects of changes brought about by maternity. For instance, in relation to stress incontinence, Sandra (FG2) said her children had asked her why she didn't go on the trampoline and she replied:

you don't like to explain to your kids that you wet yourself but I thought now my daughter's 16 'SOD IT WHY SHOULD WE HIDE THESE THINGS'...so I just explained why and she was 'OH'

Others: (laughter) wish l'd never asked

Sandra: too much information yeah (laughter)

The use of 'we' in 'why should we' implies a shared duty not to hide, and to talk about, such issues. While Sandra tried to be open with her daughter, this information was not very well received, as the others in the group recognised and acknowledged. This, and the next example, also conveyed a sense of shared experience and understanding; that women know what is being talked about and that this topic is embarrassing. Victoria (FG 3) spoke about what 'women of a certain age' were going through when she played netball with them: 
Victoria: you know all in our 30s, most of us had had kids and we were all very careful about tensing the muscles when we were jumping and leaping

Stephanie: joking, we all do it

Victoria: we do all, that's exactly, we were all laughing and joking about it cos we all knew exactly what the other ones were going through

Thus unspoken, implicit knowledge was conveyed. There was a lot of laughter in the first example and talk about joking and laughter in the second. Laughter in this context can be interpreted as an embodied response that signals awareness of judgements that might be made from real or imagined others. It, therefore, conveyed a sense of shared understanding indicating that this is an embarrassing topic. However, the seemingly humorous, comical nature of incontinence may negate its seriousness. Taken together, with something mothers 'put up with', evident in the suffering body discussed earlier, makes it more likely that health issues related to maternity may not be addressed in a timely manner.

Indeed, embarrassment and delay in seeking help in relation to stress incontinence was further emphasised by Stephanie. She said it took her several years to approach her GP, relating that she had been 'suffering with it for quite a 
long time...because it takes a bit of courage to go with something like that'. She went on to say:

and then you think ENOUGH'S ENOUGH, I can't be the only [person], so I'm just going to go grit me teeth

The use of words like 'courage' and 'grit me teeth' implies incontinence is a difficult subject to broach. The difficulty of putting incontinence into words could also be argued to reflect a lack of adequate language available to openly discuss it. That she is not the only one seemed to help Stephanie to account for approaching her doctor as it provided a way of mitigating potential embarrassment. It has been argued that stress incontinence is a 'condition of silence' as it is associated with childbirth and ageing, and because of embarrassment surrounding private bodily dysfunctions (Bradway \& Barg, 2006). Though, as Horrocks, Somerset, Stoddart and Peters (2004) note, because of the association with childbirth, men may find incontinence even more difficult to talk about. Nonetheless, the subject position that the sorority of suffering and silence makes available around certain aspects of women's bodies means mothers may not seek help or put off seeking help because of embarrassment, while also bolstering assumptions about stress incontinence being an expected, uniform and acceptable outcome of maternity.

\section{Conclusions}


Constructing changes to the maternal body in terms of aesthetics located in idealised ideologies of the White, Western beauty ideal offers limited subject positions. As the post-maternal and ageing body do not conform to ideals, embodied subjectivity can be troubled because women evaluate themselves and their bodies against young, tight and elastic standards. However, there was some resistance to, and reworking of, the aesthetic construction. Specifically, the maternal body offered protection against aesthetic concerns. Nonetheless this protection is time limited and the maternal body construction may be more difficult to sustain for younger mothers in the climate of celebrity and 'bouncing back' constructions (Nicolson et al., 2010; Roth et al., 2012) suggesting potential generational issues. However, generational issues could be further explored with a broader sample than the current study. In addition, drawing as it does on notions of 'good' and intensive mothering (Hays, 1996), the maternal construction is in opposition to the aesthetic body, thereby setting up an either/or dichotomy between the Madonna and whore; looking good and feeling sexy vs focusing on the work of maternity. This contradiction can trouble mothers' ways of being as it is difficult to sustain both constructions simultaneously.

Developing the literature on from unidimensional notions of postpartum body dissatisfaction, the body was conceptualised much more broadly than 
solely weight and shape, as is evident in both the aesthetic and maternal body constructions. Not only this, but also other constructions of the body as suffering/sentient, strong and embarrassing, indicate a certain resistance to, and shaping of, contemporary Western embodiment rather than simply succumbing to deterministic social forces. However, these further constructions also have the potential to constrain subjective embodiment due to dominant constructions of mothering as selfless, and because sacrifice and pain being normatively understood as part of birthing, idealised motherhood and medical discourse (Malacrida \& Boulton, 2012). Therefore, constructions of the maternal body as strong, as well as silences, lack of adequate language and embarrassment surrounding certain bodily dysfunction mean that mothers may not seek help and advice in a timely fashion, thus putting their health at risk. Nonetheless, the strong body construction can also offer a position of empowerment that counters more negative constructions of mothers' bodies.

The focus of the topics discussed in the groups was on longer-term changes as a result of maternity and therefore, inevitably, much of the discussion reflected this. However, changes to the body were also attributed to ageing or at least, as indicated, there was a questioning of whether they were due to maternity or ageing. Nonetheless discussion of these changes still related to aesthetics and functioning and were largely framed in terms of decline 
and loss suggesting a double bind for women in that the maternal, as well as the ageing body, are devalued.

It must be remembered that the sample in this study was mostly highly educated, mainly identified as middle-class and did not report any significant stories of difficulties in conceiving or pregnancy loss. It has been argued that dominant constructions of femininity are based on White, middle-class women (Okolosie, 2014). Thus the accounts perhaps reflect more privileged constructions of the body, precluding other embodied subjectivities including the implications of reproductive difficulties. Nonetheless, this paper offers new insights, in that, not only are the postpartum body and the 'work of mothering' inextricably linked, issues related to them also have implications for health and well-being beyond the postpartum period and as women age. Thus it can be implyed that, for those who become mothers, embodied maternal identities are in continuous process across the life course (Hollway, 2016).

\section{Acknowledgements}

The author would like to express her thanks to the participants who took part in the research and the reviewers for their helpful comments.

\section{Declaration of conflicting interests}

The author declared that there is no conflict of interest. 


\section{Funding}

This research received no specific grant from any funding agency in the public, commercial, or not-for-profit sectors.

\section{References}

Baraitser, L. (2014). Duration, skin and the ageing subject. Studies in Gender and Sexuality, 15, 228-234.

Bekker, M. H. J. (2000). The gendered body: Body and gender and the inter relationship with health. In L. Sherr, \& J. St Lawrence (Eds.) Women, health and the mind (pp. 17-32). Chichester: Wiley.

Bojorquez-Chapela, I., Unikel, C. Mendoza, M., \& de Lachica, F. (2014). Another body project: The thin ideal, motherhood, and body dissatisfaction among Mexican women. Journal of Health Psychology, 19, 1120-1131.

Bordo, S. (1993). Unbearable weight: Feminism, western culture and the body. Berkeley, CA: University of California Press.

Bradway, C., \& Barg, F. (2006). Developing a cultural model for long-term female urinary incontinence. Social Science \& Medicine, 63, 3150-3161.

Braun, V., \& Clarke, V. (2006). Using thematic analysis in psychology. Qualitative Research in Psychology, 3, 77-101. 
Braun, V., \& Kitzinger, C. (2001). The perfectible vagina: Size matters. Culture, Health \& Sexuality: An International Journal for Research, Intervention and Care, 3, 263-277.

Carter-Edwards, L., Bastian, L. A., Revels, J., Durham, H., Lokhnygina, Y., Amamoo, M., \& Ostbye, T. (2010). Body image and body satisfaction differ by race in overweight postpartum mothers. Journal of Women's Health, 19, 302-311.

Chrisler, J. C. (2011). Leaks, Lumps, and Lines: Stigma and Women's Bodies. Psychology of Women Quarterly, 35, 202-214.

Clark, A., Skouteris, H., Wertheim, E. H., Paxton, S. J., \& Milgrom, J. (2009). My baby body: A qualitative insight into women's body-related experiences and mood during pregnancy and the postpartum. Journal of Reproductive and Infant Psychology, 27, 330-345.

Day, K., Johnson, S., Milnes, K., \& Rickett, B. (2010). Exploring women's agency and resistance in health-related contexts; Contributors' introduction. Feminism \& Psychology, 20, 238-241.

Fern, V. A., Buckley, E., \& Grogan, S. (2012). Women's experiences of body image and weight loss after childbirth. British Journal of Midwifery, 20, 86065. 
Forrester, M. A. (2010). Doing qualitative research in psychology: A practical guide, London: Sage Publications.

Foucault, M. (1981). The order of discourse. In R. Young (Ed.) Untying the text: A post-structural anthology (pp. 48-78). Boston, MA: Routledge \& Kegan Paul.

Foucault, M. (1995). Discipline and Punish: The Birth of the Prison. New York: Vintage Books.

Fox, B., \& Neiterman, E. (2015). Embodied motherhood: Women's feelings about the postpartum bodies. Gender and Society, 29, 670-693.

Gavey, N. (1989). Feminist poststructuralism and discourse analysis. Psychology of Women Quarterly 13, 459-475.

Gjerdingen, D., Fontaine, P., Crow, S., McGovern, P., Center, B., \& Miner, M. (2009). Predictors of mothers' postpartum body dissatisfaction. Women and Health, 49, 491-504.

Harper, E. A., \& Rail, G. (2011). Contesting "silhouettes of a pregnant belly": Young pregnant women's discursive constructions of the body. Aporia, 3, 514. Retrieved from http://www.oa.uottawa.ca/journals/aporia/articles/2011 01/harper rail.pdf Hays, S. (1996). The cultural contradictions of motherhood. New Hale: Yale University Press. 
Hodgkinson, E. L., Smith, D. M., \& Wittkowski, A. (2014). Women's experiences of their pregnancy and postpartum body image: a systematic review and meta-synthesis. BMC Pregnancy and Childbirth, 14, 1-11.

Hollway, W. (2016). Feminism, psychology and becoming a mother. Feminism \& Psychology, 26, 137-152.

Horrocks, S., Somerset, M., Stoddart, H., \& Peters, T. J. (2004). What prevents older people from seeking treatment for urinary incontinence? A qualitative exploration of barriers to the use of community continence services. Family Practice, 21, 689-696.

Johnson, S., Burrows, A., \& Williamson, I. (2004). Does my bump look big in this? The meaning of bodily changes for first time mothers-to-be. Journal of Health Psychology, 9, 361-374.

Jordan, K., Capdevila, R., \& Johnson, S. (2005). Baby or beauty: A Q study into post pregnancy body image. Journal of Reproductive and Infant Psychology, 23, 19-31.

Malacrida, C., \& Boutlon, T. (2012). Women's perceptions of childbirth "choices": Competing Discourses of Motherhood, Sexuality, and Selflessness. Gender \& Society, 26, 748-772.

Moore, S. (2010). Is the healthy body gendered? Toward a feminist critique of the new paradigm of health. Body \& Society, 16, 95-118. 
Montemurro, B., \& Gillen, M.M. (2013). Wrinkles and Sagging Flesh: Exploring transformations in women's sexual body image. Journal of Women and Aging, 25, 3-23.

Nicolson, P., Fox, R., \& Heffernan, K. (2010). Constructions of pregnant and postnatal embodiment across three generations: Mothers', daughters' and others' experiences of the transition to motherhood. Journal of Health Psychology, 15, 575-585.

Okolosie, L. (2014). Beyond 'talking' and 'owning' intersectionality. Feminist Review, 108, 90-96.

Parker, I. (2005). Qualitative psychology: Introducing radical research. Buckingham: Open University Press.

Pauls, R. N., Occhino, J. A., \& Dryfhout, V. L. (2008). Effects of pregnancy on female sexual function and body image: A prospective study. Journal of Sexual Medicine, 5, 1915-22.

Potter, J., Edwards, D., \& Wetherell, M. (1993). A model of discourse in action. American Behavioural Scientist, 36, 383-401.

Rallis, S., Skouteris, H., Wertheim, E., \& Paxton, S. J. (2007). Predictors of body image during the first year postpartum: A prospective study. Women \& Health, 45, 87-104. 
Rodin, J., Silberstein, L., \& Striegel-Moore, R. (1984). Women and weight: A normative discontent. In T. B. Sonderegger (Ed.), Nebraska Symposium on motivation: Psychology and gender (pp. 267-307). Lincoln: University of Nebraska Press.

Roth, H., Homer, C., \& Fenwick, J. (2012). "Bouncing back”: How Australian's leading women's magazines portray the postpartum body. Women and Birth, 25, 128-134.

Shilling, C. (1993). The body and social theory. London: Sage.

Shilling, C. (2012). The body and social theory. $3^{\text {rd }}$ edition. London: Sage.

Strang, V. R., \& Sullivan, P. L. (1985) Body image attitudes during pregnancy and the postpartum period. Journal of Obstetric, Gynecologic, and Neonatal Nursing, 14, 332-337.

Thorpe, R., Fileborn, B., Hawkes, G., Pitts, M., \& Minichiello, V. (2015). Old and desirable: Older women's accounts of ageing bodies in intimate relationships. Sexual and Relationship Therapy, 30, 156-166.

Upton, R.L., \& Han, S.S. (2003). Maternity and its discontents: "getting the body back" after pregnancy. Journal of Contemporary Ethnography, 32, 670-692.

Warin, M., Turner, K., Moore, V., \& Davies, M. (2008). Bodies, mothers and identities: Rethinking obesity and the BMI. Sociology of Health and IIIness, $30,97-111$. 
Watson, B., Fuller-Tyszkiewicz,M., Broadbent, J., \& Skouteris, H. (2015). The meaning of body image experiences during the perinatal period: $\mathrm{A}$ systematic review of the qualitative literature. Body Image, 14, 102-113.

Weedon, C. (1997). Feminist practice and poststructuralist theory, $2^{\text {nd }}$ edition. Oxford: Blackwell.

Wilkinson, S. (2004). Focus group research. In D. Silverman (Ed.) Qualitative research: Theory, method and practice (pp. 177-199). London: Sage.

Willig, C. (2013). Introduction to qualitative research in psychology. Buckingham: Open University Press.

Witz, A. (2000). Whose body matters? Feminist sociology and the corporeal turn. Body \& Society, 6, 1-24.

Woolhouse, H., McDonald, E., \& Brown, S. (2012). Women's experiences of sex and intimacy after childbirth: making the adjustment to motherhood Journal of Psychosomatic Obstetrics \& Gynecology, 2012; 33, 185-190.

Young, I. M. (2005). On female body experience: Throwing like a girl and other essays. Oxford: Oxford University Press.

\section{Author Biography}


Sally Johnson is a Senior Lecturer in Psychology at the University of Bradford, UK. Her research focuses on the construction of gender in relation to women's reproductive health and motherhood. 